\title{
COMMENTS ON THE GLOBAL OCEAN OBSERVING CAPABILITIES, INDICATOR Species as Climate PROXIES, AND THE NEED FOR TIMELY OCEAN MONITORING
}

\author{
By Gary D. Sharp and Douglas R. McLain
}

\begin{abstract}
CoN leoceanography, and plate tectonics rely upon analyses of patterns within geologic strata, often characterized by biological and ecological indicators or markers. Chronostratigraphies of these sorts have been used to characterize the ocean and local climate, from understanding of arrays of fundamental, species-specific physiologically limiting parameters (e.g., temperature, oxygen, salinity, and/or fresh-water flow rates; Sharp, 1988). Chronologically ordered species-assemblage records, covering millions of years, provide the basis for much of what we know about climate history. Distributions of species that occupy ocean Transition Zones (regions of strong thermal and climatic gradients) and those that inhabit the thermal regimes on either side of these Transition Zones provide useful indicators of underlying physical regimes. In the short term, seasonal patterns and anomalies provide us with insights into watermass movements and in the longer term, El NiñoSouthern Oscillation (ENSO) and other climatedriven ocean changes.

The recent activity in support of an enhanced Global Ocean Observing System (GOOS) is welcome, although in many cases it is apparent that emphasis has been misplaced and objectives poorly prioritized. In early drafts of the GOOS requirements the major justification for implementing new enhancements has been in support of global-climate and air-sea-interaction modeling. This is a very academic and narrow view of what is needed, and unless corrected, will certainly lead toward yet another phase of minimally useful. and interrupted observing systems. One needs only recall the Ocean Station Papa experience, the near
\end{abstract}

G.D. Sharp. Cooperative Institute for Research in the Integrated Ocean Sciences. 2560 Garden Road, Monterey. CA 93940. USA. D.R. McLain, Center for Ocean Analysis and Prediction. National Oceanic and Atmospheric Administration. 2560 Garden Road, Monterey, CA 93940, USA. collapse of the CALCOFI program, and the present status of the world oceanographic fleets. Harsh economic realities emerge.

While Global Climate Modeling is a worthy objective, perhaps a more societally responsible concept around which to begin planning GOOS enhancements would be an assessment of the larger information needs of society, beginning with those who produce food, both on land and sea, and those that transport goods over the seas via boats, or airplanes. The day-to-day activities of farmers, fishermen, cargo shippers, and other world travelers are necessarily the specific targets of the weather, ocean, and climate-scale forecast models, or at least they should be. Given our personal biases, and experience within the global environmental science communities, we will concentrate more on the needs of nondefense related ocean-going communities, as they presently get little needed support from either global modelers, or the few academics that dominate the GOOS planning. There are several aspects of high-seas operations that need consideration. We have selected only a few examples that need more than lip service from oceanographers, ocean modelers, and marine meteorological forecasters.

\section{Observations, Instrumental Records, and} Information Access

One major consideration is that the instrumental records from which we have learned about the ocean and atmosphere during the last century are discontinuous. the instruments themselves are constantly under revision, and they are poorly distributed about the globe. Even in the areas where there has been maximum interest in operational oceanography. e.g.. where great proportions of the global fishery production occurs. very little observational data exist. If this situation continues, by what means will global ocean and atmosphere modelers provide the needed insights into daily-, seasonal-, and decadal-scale events and
... species-

assemblage records

provide the basis

for much of what we know about climate history. 
processes, if GOOS is only focused on the longer scales of climate concerns?

Management of marine fisheries and economic processing efficiency require detailed understanding of current oceanographic and population conditions. Long time series of historical environmental conditions are required for comparison of present situations with similar or inferred situations in the past. To attain understanding, time series on both environmental conditions and ecological status need to be compiled. All available information must be assembled, made accessible, and collated in a timely fashion so that appropriate responses can be made to synoptic environmental changes.

At present, assembly and collation of marine fishery and ocean research data are delayed while data are processed, analyzed, debated, and eventually published in scientific journals. By the time the data appear in print, the opportunity to respond to most marine events is long past. The data also must be assembled on large space scales (ocean-wide and global), because many trends important to fisheries management are best considered in these contexts. Only minor aspects can be seen in local data sets. We must assemble our ocean and fishery data sets on a global scale, in more timely ways.

We might assemble timely global data sets by taking the lead from meteorologists who have exchanged weather observations around the world in real-time for over 50 years. The World Meteorological Organization, in cooperation with the Intergovernmental Oceanographic Commission, sponsors the Integrated Global Ocean Services System (IGOSS) for real-time global exchange of ocean data. At present, most observations reported via IGOSS are expendable bathythermograph (XBT) casts from merchant and naval vessels for either climate research or military applications. The resulting near-real-time bathythermograph (BATHY) reports are mainly from deep ocean areas and provide little information on coastal waters or other areas of interest to fisheries managers. A more serious problem is that XBT casts provide no information on salinity variations and hence only minimal information on water density, stratification, and circulation. Knowledge of these properties is vital for fisheries management, as well as for climate research.

Although many CTD (conductivity-temperature-depth) casts are made by research vessels, few of the observations are reported in real-time. Each CTD cast on research vessels should be reported in real-time (as an IGOSS TEmperature-SAlinityCurrent or "TESAC" message). One of the obvious improvements for the in situ GOOS is to recruit fishing vessels, equipped with "miniCTDs", and two-way information swapping capabilities. With available technology it is possible to receive real-time ocean reports from vessels anywhere on the oceans. Reports can also be provided, in return, in the form of local and regional nowcasts and forecasts of surface and subsurface conditions for tactical fishing purposes. The development of a global network would provide bases for greatly enhanced oceanography and meteorology; as well as provide opportunity to make fishing operations more fuel efficient, and enhance resource management through better understanding of the relationships between fishing, fish, and their environment. Of course, there is no limitation implied. Any ship should be able to participate in this network, with the end result of not only increasing observation rates on the high seas, but also within the more dynamic coastal environments where many economic activities would benefit from improved information availability.

As a consequence of this somewhat broader objective, far more benefit would derive to the public, as well as industries: local fishermen, resource managers, harbor and coastal engineers, transport industries, high seas fishermen, and local tourist operations around the globe. Without a doubt, ocean-atmosphere modelers would achieve their objectives in a more directed, and expedient fashion than if the GOOS program was organized about their present conceptions of ocean-atmosphere dynamics, as modified by budget concerns within ocean-science agencies. Until the Congress and Senate appreciate the over-all impact on those industries that represent revenue sources, and the general improvement that would result in global capabilities to monitor, understand, and forecast synoptic, seasonal and longer, climate-scale processes, GOOS will remain on the "science wish list".

\section{Indicator Species and Climate Monitoring}

Due to the dominance of atmosphere and ocean physicists, satellite salespersons, and "primitive equation" modelers in planning for climate research, the value of terrestrial and ocean indicator species has not been fully recognized. Seasonal changes in chlorophyll, plants, and hydrology characterize terrestrial environments. Ocean ecosystems are usually defined using conventional species-based zoogeographic habitat descriptions. The highest resolution of climaterelated oceanographic changes, for practical purposes, are seasonal processes. Therefore, the ocean's zoogeographic structure is seasonal, following physical environmental patterns. Most of these recurrent consequences result from dynamic displacements of the transitional, highly compressed gradients in the atmospheric and subsequent oceanic features. These features include: the west wind drifts; subtropical convergences; fronts: and isotherms displacements due to local insolation, wind mixing, back-radiation or evaporation; as well as surface and subsurface current strength changes. 
Abundant historical information from environmental sampling activities and a vast array of both geological and ecological studies are available to document seasonal, annual, decadal, and longer-term responses to climate-driven environmental changes. Changes in species distributions and abundances are, in any case, prima facie evidence for climate-driven ocean variation. Of course, care must be taken to differentiate between anthropogenic and naturally induced changes.

Whereas terrestrial plants are more apparent to satellite sensors, coastal fisheries and ichthyoplankton surveys track many species as indicators of water masses and climate regimes with distinctive thermal signatures. Results of such studies have been reported for decades (c.f. reviews by Cushing, 1982, 1988; Sharp and Csirke, 1984; Southward et al., 1988). The most biologically productive areas of the global ocean are under clouds, which is one of the consequences of the physics, and the resulting biochemical activities. Studies of primary production from satellites pose dilemmas for terrestrial systems, and are even more problematic for marine systems. For example, Ropelewski et al. (1990) tested the available satellite imagery as a means for tracking climate-induced chlorophyll (terrestrial plant) changes, and they encountered predictable problems with individual platform and sensor intercalibration, and therefore interpretation difficulties.

Primary production in the ocean depends upon nutrient sources and these are associated with upwelling over local and regional scales. However, a vast majority of oceanic production for fish and mammals that are highest on the food web (apex predator species such as tunas, squids, and small cetaceans) is from areas such as the tropical western Pacific and the midocean gyres, where the primary production, as measured from either in situ sampling or from satellite surveys, is not noticeably high. There are over two million tons of tropical tunas, alone, caught each year from the western Tropical Pacific. These fishes are energetically inefficient apex predators. The tunas have an ecological efficiency of $\sim 1.5 \%$, and consume planktonic and schooling species including euphausids, squids, and other tunas (Sharp, 1983). that are also highly active, high throughput species. This implies a tremendous energy transfer. and an immense biological sequestration of new production to support fisheries of such magnitude. The supporting primary production is not well measured using standard techniques and is even less evident from satellite data. In fact. recent summaries of production measurement capabilities shows that there is no generally dependable methodology or concensus about what satellites actually measure (Chisolm and Morel. 1991).

At present the Humboldt Current System is changing from a warm, oceanic regime, domi- nated by subtropical oceanic species such as sardines, to a regime dominated by coastal faunal assemblages that are historically associated with cooler, upwelling regimens. There are several species that are useful indicators for the climate-related status of the Humboldt system. For cooler, upwelling periods, the list of dominant species includes jibia-the giant squid (Dosidicus gigas), sierra - the scabbard fish (Thyrsites atun), and the sardina comun-a local herring (Strongomera (Clupea) bentinki). The first two of these three species responded to the recent two-decade-long decrease in upwelling frequency and intensity (associated with the lower wind speeds documented by Bakun, 1990) during the recent two decades of warm-ocean periods by disappearing from the coastal fisheries between Peru and Chile $\left(42^{\circ} \mathrm{S}\right)$. The third species' range collapsed from $33^{\circ} \mathrm{S}$ to $\sim 40^{\circ} \mathrm{S}$, into a refuge area around the Gulf of Arauco. Loeb and Rojas (1988) also found that the recent cooler, upwelling periods (1984, 19851986) favored the survival of anchoveta, and an array of noncommercial upwelling system species. Also, in unpublished follow-up studies, Loeb and Rojas found that the 1986-87 warming in some way boosted the sardine reproductive success, producing another pair of healthy year classes that recruited to the fishery in late 1988 to 1990 , providing the basis for continuing the sardine fishery. However, the coastal ocean remained dominated at all locations by the upwelling species assemblages.

\section{Physicists and Empiricists: Differing \\ Perspectives}

Very different distributions of the ocean thermal regimes are present between the surface, 30 and $90 \mathrm{~m}$ depths. Consider also the transient subsurface oceanic and coastal counter currents. Advective transport of warm upper-ocean water, as in the case of the shoaling of isotherms during ENSO cool events in the eastern tropical Pacific Ocean, is one of the few general mechanisms that permits direct warming of the usually cooler, deep ocean water. The temperature transition closely approximates zoogeographic distributions because of the compression of gradients at the Transition Zones.

One result of the differences between physicists and either ecologists or fishermen is the emphasis on sea-surface temperature (SST) during the past few decades by climate and weather modelers. Their modeling assumes that SST is the ocean property of principal importance to air-sea interactions. However, the dynamic upper ocean has orders of magnitude higher heat content than does the overlying atmosphere. SST is neither an unbiased nor a particularly representative measure of thermal conditions in the upper ocean. Seasonal upper-ocean warming and cooling processes often generate a thin skin of warm (or cool) water at
Changes in species

distributions and

abundances are...

prima facie evidence

for climate-driven

ocean variation. 
... regions of greatest

apparent primary

production are...

where clouds are

present to minimize the

utility of irradiance

imagery. upper-ocean thermal boundaries, the so-called Transition Zones. These thin layers often ride over the transition zones that usually separate the welldefined ocean thermal regimes and can result in confusing information for those using SST to track subsurface ocean status.

Another confounding situation is that the most productive fisheries, and regions of greatest apparent primary production are those ocean areas where clouds are present to minimize the utility of irradiance imagery. The calibration algorithm providing the lowest root-mean-square error was $\pm 0.5^{\circ} \mathrm{C}$ in cloud-free, open ocean situations (Hilland et al., 1985). The more dynamic the cloud cover and air-sea interactions, the more likely that the errors approach $3.0^{\circ} \mathrm{C}$, a completely unacceptable level of uncertainty. Absolute SST has relatively little information content, but enormous resources are expended for its measurement (Clancy and Weller, 1992).

However, the subsurface ocean is where the most important biological action occurs. The sea surface is responsive to surface winds and therefore of considerable interest to those studying transport of early life histories of small plankters. Because most resources of interest live within the water column, for operational fisheries purposes SST is only an approximation of subsurface characteristics. Ocean skin temperature, alone, can be a misleading variable, particularly when local fishing operations are considered.

The principal synoptic applications of satellite irradiance imagery in fishery contexts is feature finding. Eddy dynamics described in local fisheries research contexts by Owen $(1981,1989)$, combined with the basin-wide subsurface dynamics of the sort exemplified by Legeckis (1986) and Busalacchi et al. (1983) certainly play important roles in the synoptic behaviors of fish, and fisheries. Yet it is population-scale changes that are of greatest interests to most fishery scientists. These vary over large, often confusing time and space scales. However, to better understand these, the more localized events and processes need to be defined and integrated into a realistic ecological wisdom. This knowledge, in turn, can be used to understand how society might better cope with both natural and anthropogenic environmental perturbations, and their ecological consequences.

The emerging ability to track the hydrologic cycle from source to sink is one of the prime potential contributions from satellite irradiance sensors. The strong statistical relation between high SST and deep convection processes does not adequately relate the fact that each deep convection cell forms quite locally.

Each cloud-tower emerges from one pixel in a satellite image, or at the base of an individual water spout, within a local ocean context. This creates a strong signature in the form of very changed thermal profiles in both ocean and atmosphere.
Study of these localized processes and their "leapfrog" transport of energy and water should lead toward a more relevant perspective of the energetics of the hydrologic cycle, particularly their effects on the upper ocean, and what to expect from a local ecological perspective.

\section{Conclusions}

We have endeavored to provide a few general examples of the social justification needed to enhance the GOOS. In some regions, the ocean environment is already being sampled frequently enough to make it possible to calibrate and compare examples collected over many years. However, it is important to have the best possible in situ global coverage to discriminate clear distinctions between interannual climate variations and secular trends. Earth system variabilities are monitored for many reasons, but methods that serve more than one purpose will be the most useful, economic alternatives to provide calibration sources for technologies where limited or no historical information exists.

Few data sets exist for physical measurements on climate time scales. There are few, or none yet from satellite technology. Although the global coverages, and dynamics are tantalizing, and inspire applications in synoptic studies and forecasts, it will be another 50 to 100 years before they become, "climate" data sets. Modeling cannot be completely substituted for empirical measurements, particularly with respect to climate changes, and the ancillary perturbations resulting from volcanism and solar activity. It will be much longer before satellite observations can be interpreted within relevant geological climate terms.

Changes in seasonal distribution patterns are attributable to climate change, where climate change can be best defined as perturbation in expected seasonal patterns due to everything above seasonal periodicities. ENSO-scale perturbations of seasonal patterns are the most apparent highfrequency climate perturbation that affects marine ecosystems. There is much more to be learned about these processes. Shorter-term, high-frequency variations, such as tides and local landsea-breeze-driven currents, and longer-term processes such as Ice Ages and Milankovich cycles are relatively well recognized. Although important to local ecosystem dynamics, these are not of particular relevance to our present commentary. $\mathrm{Hu}-$ man impacts are relevant.

We are suggesting that it is both cost effective and scientifically reasonable to track climate change in oceanic environments on many time scales using common biological observations (e.g., fisheries data) as climate status and trends monitors. These data also can be used much as one would use any combination of information, either from in situ instruments, or from terrestrial veg- 
etation records, to tie together disparate, global information, and even to calibrate satellite observations. These indicator data are often useful in other contexts, such as economics and habitat monitoring.

The problems of changing sensor technologies and relatively short-lived satellite platforms make it very difficult to support the idea that we can rely upon instrumental data, alone, for understanding climate variations. The problems go deeper. Present satellite measurement capabilities can be compared with a medical doctor trying to make a diagnosis, and prognosis, by running a thermometer over the surface of your body, and perhaps using his or her hands to feel for lumps. If this were the sole source of information about your health, or the condition of the planet, you would not feel very confident. However, a disproportionate amount of the earth observing budget has been reprogrammed into this mode of study.

Given the importance of the ocean in global climatic processes, more in situ monitoring is needed to understand climate-related processes that are manifest beyond the few decades for which good coverage from well calibrated instruments might exist. Bakun's (1991) study of coastal-upwelling regimes, trends and patterns, points out the fragilities of the available instrumental records from the last 50 years. The more recently developed, still evolving satellite technologies provide even more equivocal information from which to attempt forecasting. Yet zoogeographic, stratigraphic, and fisheries related records, in many examples, provide relatively direct information about impacts of climate-driven variabilities on ecosystems, and society.

All these problems and facts pose even more dilemmas. What set of relevant, monitorable habitat and ecological characteristics can be used to develop more meaningful models for understanding the variabilities of specific fish populations, or more appropriately, complete ecosystems? If fisheries managers are ever to truly rationalize fisheries management, they must maintain constant contact with the ocean- and climatemonitoring communities to interpret, credibly. changing local and regional fishery production and population parameters. In turn, identification of zoogeographic indicators and related physical processes should be given high priority among the information to be collated during initial global climate research. Relevant study records exist in many aquatic and fisheries research centers around the globe.

In spite of increased environmental observing capacity and growing understanding, both the communication of new concepts and the implementation of new ways of doing business (i.e., interdisciplinary research) encounter political resistance. This is only partially in response to everincreasing human demands on natural resources.
Much of the debate arises from philosophical boundaries that have emerged between the physical, biological, and socio-political sciences. It is also clear that human activities must be regulated to protect natural populations during periods of decline, particularly while they are at lower, more vulnerable abundances (Csirke and Sharp, 1983). However, the so-called collapses of fish, bird, or mammal populations that occur on decadal time scales are neither necessarily biologically catastrophic, nor necessarily the consequences of human activity. Ecosystems cannot be managed for some constant "maximum sustained population production, or condition." However, they can and should be managed for optimal recovery position from diminished states.

The patterns of change observed in zoogeographic boundaries, terrestrial or oceanic, are strong indicators of climatic conditions and trends. Many species, particularly those in aquatic environments, respond rapidly. These responses are physiologically determined; the results of millennia of ecological interaction and genetic selection. Biological systems appear to be more sensitive, and therefore more responsive to subtle environmental signals and subsequent events, than are conventional statistical or primitive-equation climate-forecasting models. Physicists need to become more aware of these alternate information sources, as means for calibrating their own tools and concepts. The merger of physiological ecology studies along with insights from zoogeographers, geologists, hydrographers, and geophysicists provide powerful tools for understanding and resolving both anthropogenic and natural climate change and provide direct information about important societal consequences as well.

\section{References}

Bakun, A., 1991: Global climate change and intensification of coastal upwelling. Science Wash. DC. 247, 198-201.

Busalacchi, A.J., K. Takeuchi and J.J. O'Brien. 1983: On the interannual wind-driven response of the tropical Pacific Ocean. In: Hydrodynamics of the Equatorial Ocean. J.C.J. Nihoul, ed., Elsevier Science Publishers, Amsterdam, 155-195.

Chisolm. S.W. and F.M.M. Morel, eds.. 1991: What controls phytoplankton production in nutrient-rich areas of the open sea? American Society of Limnology and Oceanography Symposium, San Marcos. 1991, Limnol. Oceanogr. 36. $1970 \mathrm{pp}$.

Clancy, R.M. and R.A. Weller. eds., 1992: Sea Surface Temperature: Ad Hoc Working Group Report. Joint Oceanographic Institutions Incorporated, Washington. DC. $52 \mathrm{pp}$.

Csirke. J. and G.D. Sharp. eds.. 1983: Reports of the Proceedings of the Expert Consultation to Examine the Changes in Abundance and Species Composition of Neritic Fish Resources. San Jose. Costa Rica. F.AO Fish Rep., 291. $100 \mathrm{pp}$.

Cushing. D.H.. 1982: Climate and Fisheries. Academic Press, London. 373 pp. , 1988: The Provident Sea. Cambridge University Press, Cambridge, 329 pp.
... alternate

information sources, as

means for calibrating

. . tools and concepts. 
Hilland, J.E., D.B. Chelton and E.G. Njoku, 1985: Production of global sea surface temperature fields for the Jet Propulsion Laboratory Workshop comparisons. J. Geophys. Res., 90, 11642-11650.

Legeckis, R., 1986: Long waves in the equatorial Pacific and Atlantic Oceans during 1983. Ocean-Air Interactions, $1,1-10$.

Loeb, V. and O. Rojas, 1988: Interannual variation of ichthyoplankton composition and abundance relations off northern Chile. Fish. Bull., US, 86, 1-24.

Owen, R.W., 1981: Patterning of flow and organisms in the larval anchovy environment. In: Report and Documentation of the Workshop on the Effects of Environmental Variation on the Survival of Larval Pelagic Fishes. G.D. Sharp, ed., IOC Workshop Rep. Ser., 28, 67-200. UNESCO, Paris.

, 1989: Microscale and finescale variations of small plankton in coastal and pelagic environments. J. Mar. Res., 47, 197-240.

Ropelewski, C., 1992: Real-time climate monitoring using an AVHRR vegetation index. In: Proceeding of the 8 th Annual Pacific Climate (PACLIM) Workshop, 1991,
Asilomar, California, K.T. Redmond, ed., Tech. Rep. Interagency Ecol. Studies Prog. Sacramento-San Joaquin Estuary. CL/PACLIM-IATR/92-31. Calif. Dept. Water Resources, Sacramento, 135-140.

Sharp, G.D., 1983: Ecological efficiency and activity metabolism. In: Flows of Energy and Materials in Marine Ecosystems. M. Fasham, ed., NATO Conference Series, IV, Marine Sciences, New York, 459-474.

, 1988: Neritic systems and fisheries: their perturbations, natural and man induced. In: Ecosystems of the World: Part 27. Continental Shelves. H. Postma and J.J. Zijlstra, eds., Elseviers Scientific Publishing, Amsterdam, 31-48.

and J. Csirke, eds., 1984: Proceedings of the Expert Consultation to Examine the Changes in Abundance and Species Composition of Neritic Fish Resources, San Jose, Costa Rica. FAO Fish Rep. Ser. 291, vols. 2-3. $1294 \mathrm{pp}$.

Southward, A.J., G.T. Boalch and L. Mattock, 1988: Fluctuations in the herring and pilchard fisheries of Devon and Cornwall linked to change in climate since the 16th century. J. Mar. Biol. Assoc. UK, 68, 423-445. 